\title{
“AS ESCOLAS PÚBLICAS NO BRASIL ESTÃO PREPARADAS PARA A DIVERSIDADE RELIGIOSA?"1
}

Are public schools in Brazil prepared for religious diversity?

\author{
Franciele Rodrigues ${ }^{2}$ \\ Fábio Lanza ${ }^{3}$ \\ Ileizi Luciana Fiorelli Silva ${ }^{4}$ \\ Luís Gustavo Patrocino ${ }^{5}$
}

\begin{abstract}
RESUMO: Neste trabalho procuraremos refletir sobre como a diversidade religiosa tem sido tratada no âmbito das escolas públicas. Assim, nos atentaremos, especialmente, as maneiras como as religiões de matriz africana, enquanto elemento cultural de tais povos, estão sendo abordadas no cotidiano escolar. As tradições religiosas afro-brasileiras são contempladas por atividades pedagógicas, haja vista a obrigatoriedade do ensino da História e da Cultura afro-brasileira na educação básica? Intentando responder essa inquietação, partiremos dos olhares de 711 estudantes do ensino médio pertencentes a oito escolas estaduais do Núcleo Regional de Educação de Londrina-PR. Tais amostras foram estudadas por meio da análise estatística e à luz das contribuições da Sociologia das Religiões. Verificamos que, segundo grande parte dos discentes, embora ocorreram iniciativas que valorizem a História e a Cultura Afro-Brasileira em suas escolas, ações formativas acerca das religiões de matriz africana raramente são realizadas, havendo, portanto, grande resistência no trato dessa temática em suas unidades escolares.
\end{abstract}

Palavras-chave: Diversidade; Religiões; Escola; Londrina-PR.

\footnotetext{
${ }^{1}$ Em referência a fala de Robson Arantes (Ogumsola) durante o Minicurso Diversidade Religiosa, o qual integrou as atividades do I Seminário de Educação para a Diversidade e a Equidade realizado na Universidade Estadual de Londrina (UEL).

2 Mestra em Ciências Sociais pela Universidade Estadual de Londrina (UEL). Possui graduação (habilitações licenciatura e bacharelado) em Ciências Sociais pela mesma Universidade. Atualmente cursa Jornalismo na UEL e é pesquisadora associada ao Programa Observatório da Educação (OBEDUC), ao Laboratório de Ensino, Pesquisa e Extensão de Sociologia (LENPES) e ao Laboratório de Estudos sobre as Religiões e Religiosidades (LERR). E-mail: r_franciele@hotmail.com

${ }^{3}$ Doutor em Ciências Sociais PUC-SP, atualmente docente do ensino superior no Departamento de Ciências Sociais, da Graduação, do Programa de Pós-Graduação em Ciências Sociais - Mestrado e da Especialização em Religiões e Religiosidades na Universidade Estadual de Londrina - PR (UEL). E-mail: lanza1975@gmail.com

${ }^{4}$ Doutorado em Sociologia pela FFLCH-USP (2006). É docente do Programa de Pós-graduação de Sociologia (Mestrado e Doutorado), do Mestrado Profissional de Sociologia em Rede Nacional (Associada UEL), da Especialização em Ensino de Sociologia e da graduação em Ciências Sociais da UEL. Líder do Grupo de Pesquisa do CNPq - LENPES - Laboratório de Ensino, Pesquisa e Extensão de Sociologia da UEL. Coordenadora do Observatório da Educação (CAPES - Ciências Sociais da UEL). E-mail: ileizisilva@hotmail.com

5 Mestre em Ciências Sociais, Especialista em Estatística com Ênfase em Pesquisa Quantitativa e Licenciado/Bacharel em Ciências Sociais pela Universidade Estadual de Londrina. Bacharel em Teologia pela Faculdade Evangélica do Brasil. Atua como pesquisador nos grupos: Observatório da Educação das Ciências Sociais (OBEDUC-C.S) e no Grupo de Pesquisa História, Sociedade e Religiões ambos da Universidade Estadual de Londrina. E-mail: patrocinolg@gmail.com
} 
ABSTRACT: In this work we will try to reflect on how religious diversity has been treated within the scope of public schools. Thus, we will look, especially, at the ways in which religions rooted in Africa, as a cultural element of such peoples, are being approached daily in schools. Are Afro-Brazilian religious traditions contemplated by pedagogical activities, given the obligatory teaching of Afro-Brazilian History and Culture in basic education? In an attempt to respond to this concern, we will start from the views of 711 high school students from eight state schools of the Regional Education Center of Londrina-PR. These samples were studied through statistical analysis and in light of the contributions of the Sociology of Religions. We verified that, according to a large number of students, although there were initiatives that valued Afro-Brazilian History and Culture in their schools, formative actions on religions rooted in Africa are seldom carried out, and there is therefore great resistance in dealing with this theme in their school units.

Keywords: Diversity; Religions; School; Londrina-PR.

\section{INTRODUÇÃO}

Tolerância não é igualdade. Eu sou contra a tolerância, porque ela não basta. Tolerar a existência do outro e permitir que ele seja diferente ainda é pouco. Quando se tolera, apenas se concede, e essa não é uma relação de igualdade, mas de superioridade de um sobre o outro [...] (José Saramago, Um ateu preocupando com Deus. In: Saramago nas suas palavras, 2010).

Neste trabalho ensejamos pensar sobre a diversidade religiosa no âmbito das escolas públicas, atentando-nos para como essa instituição social tem abordado a história e as manifestações referentes as religiões de matriz africana em seu dia a dia. Comporão nossa reflexão sobre a temática, 711 questionários respondidos por estudantes do ensino médio regular e integrado à educação profissional concernentes a oito escolas públicas do Núcleo Regional de Educação de Londrina-PR.

Tais amostram foram coletadas por meio da pesquisa " $O$ ensino médio no Brasil: análise comparativa das múltiplas desigualdades socioeducacionais nas microrregiões do Paraná”, em desenvolvimento pelo Programa Observatório da Educação (OBEDUC) vinculado ao departamento de Ciências Sociais da Universidade Estadual de Londrina (UEL) ${ }^{6}$.

Centramos nossa atenção à diversidade religiosa nos espaços escolares, especialmente a presença das religiões afro-brasileiras por essas serem as principais vítimas de fanatismo religioso no país. De acordo com informações apresentadas pelo

\footnotetext{
6 Mais informações sobre o projeto podem ser consultadas no seguinte endereço eletrônico: http://www.uel.br/cch/soc/portal/pages/projetos/obeduc.php.
} 
Mapa da Intolerância Religiosa, divulgado em 2011, e responsável por apresentar um levantamento das violências ${ }^{7}$ motivadas por preconceito religioso nos últimos dez anos em território nacional contra os diversos coletivos religiosos como judeus, católicos, muçulmanos, africanos, neopentecostais, as religiões de matriz africana são os alvos mais recorrentes de tais crimes no Brasil.

Tais atentados têm acontecido em múltiplos contextos sociais, em regiões diversas do país e envolvendo diferentes agentes. Como exemplos que ocorreram em ambientes públicos podemos citar os casos de uma menina de 11 anos que foi apedrejada ao deixar um culto de candomblé na Zona Norte do Rio de Janeiro ${ }^{8}$, também uma estudante de 14 anos que foi agredida dentro de uma escola situada na capital do Estado do Paraná, Curitiba ${ }^{9}$. A aluna foi chutada por colegas de sala que diziam não querer aproximação com ela que era da "macumba", ambos os ataques datam de 2015.

Mais recentemente, em julho de 2017, após a depredação de um terreiro de candomblé localizado na região de Belo Horizonte, a justiça mineira decidiu pelo cerceamento da liberdade de culto da casa ${ }^{10}$. Foi estabelecido um conjunto de regras que deviam ser seguidas para a celebração dos cultos, esses deveriam ser realizados apenas às quartas-feiras e em um único sábado do mês. Caso venha a descumprir a regulamentação, o terreiro é responsabilizado a pagar uma multa diária no valor de $\mathrm{R} \$ 100,00$.

É explícito o posicionamento parcial do Estado nesse episódio que optou por punir novamente o grupo religioso já violado por outros segmentos da sociedade civil. Ademais, um dos casos mais recentes de intolerância religiosa contra as religiões de origem africana, marca de setembro de 2017. Um grupo de homens armados invadiram

\footnotetext{
${ }^{7}$ Compreendemos que a intolerância pode manifestar-se por diferentes modos: seja pela violência física e/ou por violência simbólica. Essa última segundo Bourdieu (2000) corresponde ao mecanismo que faz com que os indivíduos vejam e assimilem naturalmente as ideias e valores dominantes. É desenvolvida pelos agentes e instituições sociais que usam dela para manter sua posição hegemônica e, portanto, de exercício do poder sobre os grupos subordinados.

${ }^{8}$ Ver em: http://g1.globo.com/rio-de-janeiro/noticia/2015/06/menina-vitima-de-intolerancia-religiosa-dizque-vai-ser-dificil-esquecer-pedrada.html.

${ }^{9}$ Ver em: https://extra.globo.com/noticias/brasil/estudante-agredida-por-intolerancia-religiosa-dentro-deescola-nao-quer-voltar-ao-colegio-17650415.html.

10 Ver em: http://justificando.cartacapital.com.br/2017/07/20/justica-impoe-regras-para-cultos-decandomble-em-mg/.
} 
um terreiro de candomblé localizado em Nova Iguaçu na Baixada Fluminense no Rio de Janeiro e obrigaram a mãe de santo a destruir os seus próprios símbolos religiosos ${ }^{11}$.

O ultraje foi gravado por e vastamente disseminado nas redes sociais. No vídeo é possível identificar as seguintes passagens: "Quebra tudo, quebra tudo! Apaga as velas, porque o sangue de Jesus tem poder! Arrebenta todas as guias! Todo mal tem que ser desfeito em nome de Jesus! Quebra tudo porque a senhora é quem é o demônio-chefe! É a senhora que patrocina essa cachorrada! Quebra tudo! Arrebenta as guias todas, derrama, quero que quebre as guias todas".

A nível local também presenciamos casos de discriminação religiosa ${ }^{12}$. Nessa perspectiva, no dia 22 de setembro de 2017 foi realizado nas dependências do Centro de Letras e Ciências Humanas $(\mathrm{CLCH})$ da UEL o "I Seminário Educação para a Diversidade e Equidade". Entre as atividades do evento foi desenvolvido um minicurso com a temática: "Diversidade Religiosa" que contou com a participação de Robson Arantes (Ogumsola), representante da Associação de Ogans de Londrina-PR e região. O depoimento do convidado apresentou, além da inquietação que dá título a esse trabalho, também denúncias de racismo religioso que vão desde xingamentos, motorista de ônibus que não para no ponto de embarque quando o vê com as vestimentas brancas e portando suas guias até à ameaças de morte.

À vista disso, acreditamos que refletir sobre os casos de intolerância religiosa que acometem as religiões afro-brasileiras torna-se uma tarefa de grande necessidade e urgência. Para tanto, consideramos ser preciso retrocedermos ainda que brevemente em nossa história a fim de compreendermos como foram se formando os estigmas ${ }^{13}$ e as tensões entre tais crenças e as expressões religiosas cristãs, essas últimas majoritárias em

11 Ver em: http://cbn.globoradio.globo.com/editorias/policia/2017/09/13/CRIMINOSOS-OBRIGAMMAE-DE-SANTO-A-DESTRUIR-PROPRIO-TERREIRO-EM-NOVA-IGUACU.htm.

${ }^{12}$ Outro crime de intolerância religiosa que ocorreu em Londrina-PR e adquiriu repercussão nacional data de 2013. A líder do movimento negro e mãe de santo, Vilma Santos de Oliveira, conhecida como Yá Mukumby, sua mãe Allial Santos de Oliveira e a sua neta Olivia Santos de Oliveira foram assissanadas em sua própria casa por um vizinho.

${ }^{13}$ De acordo com as contribuições de Goffman (2004) acerca da ideia de estigma: "Enquanto o estranho está à nossa frente, podem surgir evidências de que ele tem um atributo que o torna diferente de outros que se encontram numa categoria em que pudesse ser - incluído, sendo, até, de uma espécie menos desejável num caso extremo, uma pessoa completamente má, perigosa ou fraca. Assim, deixamos de considerá-lo criatura comum e total, reduzindo-o a uma pessoa estragada e diminuída. Tal característica é um estigma, especialmente quando o seu efeito de descrédito é muito grande - algumas vezes ele também é considerado um defeito, uma fraqueza, uma desvantagem - e constitui uma discrepância específica entre a identidade social virtual e a identidade social real" (GOFFMAN, 2004, p.06). 
número de membros no país, embora, o campo religioso brasileiro seja marcado por uma multiplicidade de manifestações religiosas que ora diversificam-se, ora aproximam-se por meio dos movimentos sincréticos.

Nesse sentido, Paula Monteiro (2006) e Marcelo Camurça (2009) nos trazem contribuições importantes. Segundo os autores, desde o Brasil Colônia a tradição religiosa europeia, predominantemente católica, buscou assimilar a cultura nativa dos povos indígenas e africanos. Intersecções ou recorrendo as palavras de Camurça (2009) "contaminações mútuas" marcaram as relações entre os universos religiosos católico, indígena e africano. Entretanto, como é sabido, essas interações não aconteceram sem conflitos, isto porque, a todas as religiões cabiam assemelhar-se as práticas e visões de mundo do catolicismo. Danças e transes, por exemplo, eram demonizadas pela Igreja Católica.

Assim, manifestações religiosas populares, não institucionalizadas passaram a ser classificadas como "magia negra", "charlatanismo", "bruxaria" e, então, representavam uma ameaça à ordem social vigente, sendo necessário persegui-las e coibilas. É conhecido que as religiões afro-brasileiras conseguiram sobreviver a repressão sofrida por meio do sincretismo afro-católico e também pela incorporação de elementos do espiritismo: "vimos que para poder subsistir durante todo o período escravista os deuses negros foram obrigados a se dissimular por trás da figura de um santo ou de uma virgem católica" (BASTIDE, 1985, p.359).

Diante disso, de acordo com Monteiro (2006) o catolicismo constitui-se como uma espécie de: "língua universal da tradução de qualquer prática em rito religioso e o referencial de uma publicização legítima" (MONTEIRO, 2006, p.61). A partir da Constituição da República de 1891, o catolicismo deixou de ser religião oficial em nosso Estado, porém, é preciso pontuarmos que tal separação não extirpou a deslegitimação com que os poderes públicos e outros segmentos sociais despendem as religiões afrobrasileiras, vide os episódios de intolerância religiosa contratais grupos, como ilustramos anteriormente.

Com base nessas considerações, julgamos que debater sobre a diversidade religiosa nos espaços escolares na atual conjuntura sócio histórica que atravessamos configura-se uma forma de resistência as investidas antidemocráticas que a educação brasileira tem sofrido com a ascensão de movimentos reacionários como o Escola "sem" 
Partido, que buscam, entre outros efeitos, extinguir do cotidiano escolar as discussões sobre diversidade sexual e de gênero, também acerca da pluralidade religiosa, entre outros demarcadores sociais. Contrários a esses projetos que anseiam um modelo educacional discriminatório e excludente, uma vez negligencia um preparo para o respeito às diferenças sociais, intentamos nesse ensaio refletir acerca da edificação de uma escola mais inclusiva (e viva) para todos os segmentos sociais.

\section{"DEUS SIM, ORIXÁS NÃO"14: A AUSÊNCIA DOS DEBATES SOBRE AS RELIGIÕES AFRO-BRASILEIRAS NAS ESCOLAS PÚBLICAS}

Como é sabido o espaço escolar é um ambiente de conflito de diferentes ordens, desde os problemas administrativos como sala de aulas superlotadas, também pedagógicos como a falta de professores ou de materiais didáticos e tão importantes quanto os problemas sociais, como a discriminação racial e a intolerância religiosa. Tendo em vista esses desafios que apresentam-se as escolas, por meio de nossa pesquisa também objetivamos apreender como essa esfera pública tem tratado as diferenças de gênero, étnico-raciais e religiosas.

Nesse momento de nosso ensaio centraremos nossos esforços nas discussões sobre as diversidades étnico-racial correlacionando-as a pluralidade religiosa no ambiente escolar. Diante disso, questionamos: As escolas têm sido sensíveis as tais desigualdades? Têm realizado debates que abordem essas temáticas? De acordo com os estudantes, há casos de preconceito racial e religioso nas unidades escolares pesquisadas? Como as religiões de matriz africana têm sido percebidas dentro dos espaços escolares?

No entanto, antes de prosseguirmos tentando responder tais inquietações, consideramos importante traçarmos os perfis dos jovens que participaram da nossa investigação. Como já apontado, integraram nosso estudo 711 alunos de oito escolas estaduais localizadas na cidade de Londrina-PR e região metropolitana. Tais estudantes frequentam o ensino médio regular $(91,56 \%)$ e o ensino médio integrado à educação profissional $(6,33 \%)$.

\footnotetext{
${ }^{14}$ Em referência a fala de Robson Arantes (Ogumsola) durante o Minicurso Diversidade Religiosa, o qual integrou as atividades do I Seminário de Educação para a Diversidade e a Equidade realizado na Universidade Estadual de Londrina (UEL).
} 


\section{relegens thrésketa}

Foram contemplados discentes do primeiro ano do ensino médio (33,03\%), do segundo ano do ensino médio $(34,25 \%)$ e do terceiro ano do ensino médio $(32,72 \%)$. A maioria dos alunos estudam no período matutino $(77,92 \%)$, mas também agregam a nossa investigação estudantes que frequentam a escola à noite $(21,52 \%)$ e à tarde $(0,56)$. Salientamos que, geralmente, o ensino médio é ofertado nos horários da manhã e da noite, o que explica a pequena participação de alunos do turno vespertino em nossa pesquisa.

A maior parte dos jovens identificaram-se como mulheres $(58,37 \%)$, já homens registram (41,21\%). No entanto, quando questionados acerca de suas identidades de gênero, $(55,98 \%)$ indicaram o gênero feminino e $(38,40 \%)$ apontaram o gênero masculino, já $(5,20 \%)$ não responderam e $(0,42 \%)$ classificaram outros. Por meio de tais informações, notamos que não há uma correspondência intrínseca entre o sexo e a identidade de gênero dos indivíduos, tal como defendem interpretações de viés biológico das relações de gênero.

No diz respeito a orientação sexual, os estudantes, majoritariamente, declararamse como heterossexuais $(86,22 \%)$, já $(5,49)$ consideraram-se bissexuais, $(4,50)$ não responderam e $(3,38 \%)$ identificaram-se como homossexuais. Acerca das origens étnicoraciais, o total de alunos brancos foi superior, atingindo a marca de $(46,84 \%)$, seguidos dos estudantes que declararam-se pardos $(36,57 \%)$, negros $(11,11 \%)$, amarelos $(3,52 \%)$ e indígenas $(1,97 \%)$. Todavia, se juntarmos o contingente de discentes que disseram-se pardos e aqueles que classificaram-se como negros, totalizamos (47,68\%), o que ultrapassa o número de jovens brancos.

No que refere-se ao vínculo religioso, a maior parte dos estudantes declarou possuir religião $(81,43 \%)$ enquanto $(18,57 \%)$ afirmaram que não detêm nenhuma adesão religiosa. Observamos, então, que os alunos entrevistados não estão distanciando-se das religiões e religiosidades na contemporaneidade. Entre os que são religiosos, predominaram em nosso estudo os jovens católicos (43,52\%), porém, com uma ínfima diferença em relação ao número de alunos "evangélicos" 15 (41,80\%). Essa evidência não difere-se do movimento que tem sido observado no campo religioso brasileiro, cujo catolicismo tem perdido fiéis. Segundo dados do Datafolha no ínterim de 2000 a 2010, o total de católicos no país decresceu de 73,06\% para 64,06\%.

\footnotetext{
15 Pontuamos que empregamos o termo "evangélicos" a fim de expressar as diferentes religiões que compõem esse grupo social, a saber: protestantes históricos, pentecostais, neopentecostais. Entretanto, não desconsideramos as heterogeneidades que existem entre tais manifestações religiosas.
} 
Em contrapartida, nessa mesma década (2000-2010) as religiões do segmento "evangélico" (protestante histórica, pentecostal, neopentecostal) aumentaram o número de seus seguidores de modo que o total de "evangélicos" no Brasil cresceu de 26,2 milhões para 42,3 milhões. No que tange as diversidades, buscamos, inicialmente conhecer se os jovens já haviam sofrido algum tipo de discriminação. Como podemos perceber pela tabela abaixo a discriminação estética (obesidade, magreza ou outra característica física) foi a mais indicada pelos estudantes, atingindo a marca de $(32,07 \%)$, a discriminação religiosa foi a segunda mais citada, com o índice de $(11,25 \%)$, superando, portanto, a discriminação racial e a de gênero, que obtiveram $(10,13 \%)$ e $(6,89 \%)$, respectivamente.

Tabela 1. Você já se sentiu vítima de algum tipo de discriminação? Se necessário, marque mais de uma alternativa.

\begin{tabular}{|c|c|c|}
\hline Resposta & Contagem & Percentagem \\
\hline Não sofri & 351 & $49,37 \%$ \\
\hline $\begin{array}{c}\text { Estética (obesidade, magreza ou outra } \\
\text { característica física) }\end{array}$ & 228 & $32,07 \%$ \\
\hline Religiosa & 80 & $11,25 \%$ \\
\hline Racial & 72 & $10,13 \%$ \\
\hline Social/Econômica & 58 & $8,16 \%$ \\
\hline Gênero & 49 & $6,89 \%$ \\
\hline Outros & 5 & $0,70 \%$ \\
\hline
\end{tabular}

Fonte: Pesquisa OBEDUC Ciências Sociais UEL

$\mathrm{Na}$ sequência, perguntamos em qual contexto os alunos sofreram tais discriminações. Como podemos acompanhar pela próxima tabela, o ambiente escolar é indicado pela maioria dos discentes $(70 \%)$ :

Tabela 2. Em qual contexto?

\begin{tabular}{|c|c|c|}
\hline Resposta & Contagem & Percentagem \\
\hline Em seu ambiente de estudo & 252 & $70 \%$ \\
\hline Em ocasiões sociais (entre amigos ou local público) & 156 & $43,33 \%$ \\
\hline Na família & 88 & $24,44 \%$ \\
\hline
\end{tabular}




\begin{tabular}{|c|c|c|}
\hline Em seu ambiente de trabalho & 22 & $6,11 \%$ \\
\hline
\end{tabular}

Fonte: Pesquisa OBEDUC Ciências Sociais UEL

A seguir buscamos saber se nas escolas investigadas são realizadas atividades que abordem a cultura negra. De acordo com a maioria dos estudantes são desenvolvidas atividades que valorizam a cultura negra em suas escolas. As respostas sugerem que essas acontecem, principalmente, no decorrer do ano $(35,58 \%)$ e na semana de comemoração da consciência negra $(23,49 \%)$, conforme a tabela seguinte nos esclarece:

Tabela 3. Na sua escola em que você estuda são desenvolvidas atividades que valorizem a cultura negra?

\begin{tabular}{|c|c|c|}
\hline Resposta & Contagem & Percentagem \\
\hline $\begin{array}{c}\text { Sim, são desenvolvidas atividades no decorrer } \\
\text { do ano }\end{array}$ & 253 & $35,58 \%$ \\
\hline $\begin{array}{c}\text { Sim, porém somente na semana } \\
\text { comemorativa da consciência negra }\end{array}$ & 167 & $23,49 \%$ \\
\hline Não me lembro & 157 & $22,08 \%$ \\
\hline Não temos nenhuma atividade & 106 & $14,91 \%$ \\
\hline Sem resposta & 28 & $3,94 \%$ \\
\hline
\end{tabular}

Fonte: Pesquisa OBEDUC Ciências Sociais UEL

Porém, como podemos ver pela tabela abaixo constatamos que segundo a maioria dos estudantes os estudos sobre as religiões de matriz africana "quase nunca" são abordados em sala de aula:

Tabela 4. As religiões de matriz africana (candomblé, umbanda, entre outras) são abordadas em sala de aula?

\begin{tabular}{|c|c|c|}
\hline Resposta & Contagem & Percentagem \\
\hline Quase nunca & 273 & $38,40 \%$ \\
\hline Não me lembro & 150 & $21,10 \%$ \\
\hline Nunca & 140 & $19,69 \%$ \\
\hline Diversas vezes ao ano & 71 & $9,99 \%$ \\
\hline Frequentemente & 49 & $6,89 \%$ \\
\hline Sem resposta & 28 & $3,94 \%$ \\
\hline
\end{tabular}

Fonte: Pesquisa OBEDUC Ciências Sociais UEL 
Notemos que se juntarmos a quantidade de alunos que disseram que "quase nunca" as religiões afro-brasileiras são contempladas nas atividades escolares com aqueles que afirmaram que "nunca" as mesmas são vistas, atingiremos o índice de $(58,09 \%)$. Ora, com isso, identificamos um paradoxo! Se de acordo com grande parte dos estudantes de nossa pesquisa são desenvolvidas iniciativas que valorizam a cultura negra em suas respectivas escolas, por que não são discutidas as religiões afro-brasileiras, vide que essas são um dos elementos que compõem a cultura de tais coletivos étnico-raciais?

A professora Stela Guedes associada ao Programa de Pós-Graduação em Educação da Universidade do Estado do Rio de Janeiro (UERJ) nos auxilia a pensar sobre essa problemática. A estudiosa analisou ocorrências de intolerância contra as religiões de matriz africana nos espaços escolares, bem como, os obstáculos para a implementação da Lei $10.639^{16}$. Entre as suas verificações está a indicação que as escolas são os locais em que os alunos membros de tais denominações religiosas mais se sentem discriminados. Diante disso, não podemos desconsiderar a intolerância religiosa como um dos fatores que podem levar ao abandono escolar. Em um dos trechos de uma entrevista concedida pela pesquisa ao Portal Aprendiz (UOL), ela afirma:

Em mais de 20 anos de pesquisa todas as crianças e jovens do candomblé são unânimes quando afirmam que todos os espaços da sociedade são cruéis, mas nenhum lugar é tão cruel quanto a escola quando se trata de humilhar e excluir alunos e alunas de candomblé ou umbanda. ${ }^{17}$

Exercício similar de investigação acerca do ensino das religiões afro-brasileiras por meio da Lei 10.639 foi realizado por Bakke (2011), especificamente, no Estado de São Paulo. A autora, que desenvolveu entre suas técnicas de pesquisa a análise de materiais pedagógicos, de cursos de formação continuada docente e etnografia em três escolas, nos traz evidências a fim de refletirmos sobre a ausência das discussões relativas as religiões afro-brasileiras e também sobre quais são as dificuldades em promover tais debates nas escolas.

\footnotetext{
${ }^{16}$ Estabelecida em 2003 a referida legislação define a obrigatoriedade do ensino da História e Cultura Afrobrasileira na educação básica e ensino superior.

17 A referida entrevista pode ser consultada integralmente no seguinte endereço eletrônico: http://portal.aprendiz.uol.com.br/2015/05/12/escola-e-o-espaco-onde-criancas-de-religioes-afro-mais-sesentem-discriminadas-afirma-pesquisadora/.
} 


\section{relegens thrésketa}

De acordo com Bakke (2011) na maioria das vezes o ensino da História e Cultura Africana e Afro-brasileira nos cotidianos escolares fica a cargo dos professores responsáveis pelas disciplinas de Ciências Humanas, como História, Artes, Literatura, Sociologia, Filosofia e Geografia. Logo, as atividades ocorrem de maneira pontual, em determinados momentos do ano letivo, comumente, em lembrança às datas comemorativas como o Dia da Consciência Negra celebrado em 20 de novembro. A pesquisadora classifica tais ações como uma "Pedagogia do evento", uma vez que, não caracterizam um trabalho permanente e conjunto por parte das equipes pedagógicas e nem mesmo mobilizam toda comunidade escolar.

Além disso, outro problema identificado pela autora versa sobre os livros didáticos. Esses, embora estejam avolumando-se desde a publicação do marco legal, ainda permanecessem orientados pelo ensino cronológico, ou seja, pela apresentação da História da África de modo superficial, não contribuindo, assim, para uma educação de perspectiva mais desmistificadora das relações de poder que envolvem as interações entre os grupos étnico-raciais diversos. Em outros casos, alguns exemplares reproduzem estereótipos apresentando, por exemplo, imagens de indivíduos negros desempenhando apenas papeis marginalizados socialmente. Uma amostra disso se dá pela designação dos negros ao exercício de profissões de menor prestígio social. Também através das representações que apresentam a mulher negra, a "mulata", de maneira objetificada e hipersexualizada.

Ainda, como nos lembra Bakke (2011) a intolerância religiosa contra as religiões de matriz africana nas escolas pode ocorrer de diferentes maneiras como a resistência de membros das equipes pedagógicas, professores e alunos em participar de momentos de formação sobre a temática, o impedimento posto a alunos iniciados no candomblé a frequentar as salas de aula portando as suas guias, o boicote as ações que envolvam o assunto e, para mais, o medo em propor o debate frente a reação das famílias dos estudantes, demais profissionais da escola, entre outros sujeitos.

Desse modo, assim como vislumbramos em nossa pesquisa, para a pesquisadora dentre as questões e elementos que compõem a História e a Cultura Africana e Afrobrasileira suscitar a discussão acerca das religiões afro-brasileiras nas unidades escolares figura como um dos maiores desafios, isto porque, há na sociedade brasileira a predominância de uma percepção deturpada de tais crenças, que acabam por associá-las 
as ideias pejorativas de "coisas do Diabo", "macumba", "bruxaria", entre outros preconceitos.

Não obstante, Bustos, Lanza e Patrocino (2016) dedicaram-se a analisar casos de intolerância religiosa em duas escolas públicas em Londrina-PR. As observações dos pesquisadores indicaram que durante o desenvolvimento do ofício docente, os professores pertencentes às religiões de matriz cristã demonstram grande dificuldade em lidar com indivíduos que possuem filiações religiosas diversas as suas, sobretudo, as religiões afrobrasileiras, o que pode ser constatado pela coleta das seguintes expressões pelos autores: "discriminação da religião afro”, "[preconceito] em relação as religiões afrodescendentes", "[desrespeito] a religião afro", "contra a macumba”.

Concordamos com os autores que sugerem a importância de cursos de formação continuada que promovam discussões sobre a pluralidade religiosa na sociedade brasileira e, sobremaneira, nas escolas públicas para os quadros de professores dos diferentes níveis de ensino da educação básica (educação infantil, ensino fundamental, ensino médio). Nesse sentido, em um levantamento que realizamos em 2016 na UEL identificamos que apenas a licenciatura em Ciências Sociais entre os quinze voltados à qualificação para a docência oferecidos pela Universidade ofertava uma disciplina, de caráter optativo ressalta-se, que contempla, entre outros conteúdos sobre as religiões e as religiosidades, a diversidade religiosa (LANZA; RODRIGUES; SILVA, 2017).

Torna-se evidente, portanto, que a desnaturalização das percepções negativas conferidas as religiões de matriz africana é um exercício por se fazer. Nesse horizonte, embora Elisa Rodrigues (2013) privilegie em seus estudos as questões referentes a disciplina de ensino religioso, como a formação de professores para esse componente curricular, definição de quais conteúdos curriculares devem ser ensinados e por quais metodologias de ensino, recorremos as suas considerações buscando pensar sobre as interações entre os fenômenos religiosos e as escolas públicas mais amplamente, especialmente, no que diz respeito aos conflitos que se estabelecem entre os diferentes grupos religiosos nessa esfera pública.

Chamamos a atenção para a noção de tolerância discutida pela autora. Essa deverá prezar pelo estabelecimento da coexistência respeitosa entre os diversos coletivos religiosos no dia a dia das escolas, buscando, portanto, desconstruir visões fundamentalistas que tendem a valorizar as suas crenças em detrimento das demais. Desse 
modo, é preciso considerarmos que não raro as religiões utilizam discursos totalizadores que reivindicam aos seus dogmas e rituais as ideias de verdade e universalidade.

Vislumbramos, assim, a tolerância como uma capacidade imprescindível para que se caminhe rumo ao reconhecimento, que ao nosso ver, é ainda mais significativo. Reconhecer os outros como sujeitos de direitos, como aqueles que assim como "nós" tem liberdade para professar e vivenciar (ou não) a sua fé. Esse movimento implica uma mudança na forma como olhamos para a nossas crenças e as dos outros sujeitos, procurando relativizá-las: o não reconhecimento consiste na depreciação de tal identidade pela cultura dominante e o consequente dano à subjetividade dos membros do grupo. Reparar esse dano significa reivindicar reconhecimento" (FRASER, 2007, p.122).

No entanto, como garantir esse garantir essa postura de tolerância, e acima de tudo, reconhecimento? Para isso, acreditamos que o conhecimento sobre as diferentes religiões, suas narrativas, premissas, símbolos, ritos, mitos, constitui-se como um dos aliados no combate à discriminação religiosa. Gerar debates sobre as diversidades nos espaços escolares é avistá-los como locais que propiciam o encontro entre sujeitos de diferentes origens econômicas, com múltiplas crenças religiosas (o que também inclui não possui uma religião), de pertencimentos étnico-raciais distintos que trazem suas vivências para esse ambiente social, se comunicam, interagem. Estabelecem processos de trocas e conflitos. Não seria esse um dos principais locais para que os indivíduos aprendam a lidar com as diferenças?

\section{CONSIDERAÇÕES FINAIS}

Neste trabalho procuramos conhecer se as religiões afro-brasileiras são abordadas em sala de aula de acordo com as percepções dos estudantes do ensino médio de escolas públicas do Núcleo Regional de Educação de Londrina-PR. Assim, evidenciamos que segundo a maioria dos alunos são desenvolvidas nas escolas pesquisadas ações que valorizam a cultura negra.

Entretanto, não são desenvolvidas em sala de aula discussões sobre as religiões afro-brasileiras. Diante do que foi discutido, observamos que trazer para as instituições escolares debates sobre tais tradições tem sido um grande desafio, mesmo após o estabelecimento da Lei 10.639. Mas, se as religiões expressam um dos elementos da cultura dos povos africanos porque não trazer esse assunto para a ciência dos alunos? 
Vimos que ao longo dos séculos as religiões de matriz africana são as que mais tem sofrido com a intolerância religiosa no país. Frequentemente presenciamos crimes de natureza religiosa praticados contra terreiros, casas de santo ou ataques aos seus membros, proibição às suas manifestações, ainda que esses nem sempre sejam tipificados como crimes de intolerância religiosa pelo Estado. Esse último, muitas vezes, também tem violado as práticas religiosas afro-brasileiras, na medida em que não asseguram a sua liberdade de existência e expressão.

Retomando o questionamento que levou a feitura desse trabalho: "as escolas públicas no Brasil estão preparadas para a diversidade religiosa? "Ressaltamos que ao elaborarmos essa pergunta não intentamos defender que as escolas públicas promovam quaisquer tipos de proselitismo religioso ${ }^{18}$. Ao contrário disso, entendemos esses espaços não devem subordinar uma crença a outra, isto é, desvalorizar uma religião para exaltar e promover outra, mas sim propiciar a desmistificação das relações assimétricas que historicamente têm sido construídas entre os grupos religiosos.

Sob esse prisma, compreendemos que a postura tolerante, premissa para o desenvolvimento do reconhecimento, é democrática na medida em que reconhece a religião do outro enquanto legitima, a confere dignidade, não a esvazia de significado. Dito de outro modo, a tolerância religiosa torna-se condição para a efetividade dos regimes democráticos. Nesses contextos, os poderes públicos devem prezar para que as distintas religiões possuam o seu espaço de culto, de expressão com liberdade, igualdade e respeito. A supressão de quaisquer manifestações religiosas configura-se como um ataque aos direitos humanos.

Por fim, reforçamos a necessidade de promovermos ações voltadas à formação de professores que sejam sensíveis a pluralidade religiosa e a todas as diversidades sociais (de gênero, sexual, étnico-racial, econômica, regional), uma vez que vislumbramos que esse profissional pode atuar como um dos mediadores entre os conflitos entre os

18 “O proselitismo religioso se caracteriza pela difusão de um conjunto de ideias, práticas e doutrinas que se auto referenciam como verdade. Durante todo o período Colonial e Imperial, a estreita relação entre estado e igreja legitimou o proselitismo na instrução pública, assim como discursos e práticas de negação da diversidade religiosa e de subalternização das crenças, saberes, identidades e culturas que se distinguiam do padrão sociocultural estabelecido. Mesmo com a Proclamação da República, e a consequente separação constitucional dos poderes políticos e religiosos, o proselitismo ainda se configura no contexto e cotidiano escolar" (BRASIL, 2016, p.171). 
diferentes grupos sociais e, para mais, poderá contribuir para a desconstrução das desigualdades entre eles.

\section{REFERÊNCIAS BIBLIOGRÁFICAS}

BAKKE, Rachel R. B. Na escola com os orixás: o ensino das religiões afro-brasileiras na aplicação da Lei 10.639. Tese de doutorado apresentada ao Programa de PósGraduação em Antropologia Social do departamento de Antropologia da Faculdade de Filosofia, Letras e Ciências Humanas da Universidade de São Paulo (USP), 2011.

BASTIDE, Roger. As religiões africanas no Brasil: contribuição a uma sociologia das interpretações de civilizações. Tradução de Maria Eloísa Capellato e Olívia Krähenbühl. São Paulo: Livraria Pioneira Editora, 2ª ed., 1985.

BOURDIEU, Pierre. O Poder Simbólico. Pierre Bourdieu; tradução Fernando Tomaz (português de Portugal) - $3^{\text {a }}$ ed. - Rio de Janeiro; Bertrand Brasil, 2000.

BRASIL. Base Nacional Comum Curricular (BNCC). Disponível em: http://basenacionalcomum.mec.gov.br/\#/site/inicio. Acesso em: 29 de junho de 2017.

BUSTOS, Vinicius dos S. M.; LANZA, Fábio.; PATROCINO, Luis G. As práticas religiosas dos professores nas escolas de Londrina: uma análise sobre a intolerância religiosa. In: Caderno de ANAIS V Seminário Internacional de Práticas Religiosas no Mundo Contemporâneo (LERR/UEL), Londrina: UEL, 2016.

CAMURÇA, Marcelo. Entre sincretismos e "guerras santas". Revista USP. São Paulo, n. 81, março/maio 2009.

FRASER, Nancy. Reconhecimento sem ética? Revista Lua Nova, USP. São Paulo, 70: 101-138, 2007.

GOFFMAN, Erving. Estigma - notas sobre a manipulação da identidade deteriorada. Publicação original: 1988. Digitalização: 2004.

GUALBERTO, Marcio Alexandre M. Mapa da intolerância religiosa - 2011. Violação ao Direito de Culto no Brasil. Rio de Janeiro, 2011.

LANZA, Fábio.; RODRIGUES, Franciele.; SILVA, Ileizi L. Fiorelli. Diversidade religiosa nas escolas públicas: olhares para a formação de professores. In: Caderno de ANAIS VI Seminário Internacional de Práticas Religiosas no Mundo Contemporâneo (LERR/UEL), Londrina: UEL, 2017.

MONTEIRO, Paula. Religião, Pluralismo e Esfera Pública no Brasil. Novos Estudos. São Paulo: CEBRAP, n. 74, mar 2006.

RODRIGUES, Elisa. Ensino religioso, tolerância e cidadania na escola pública. Numen, Juiz de Fora, v. 16, n. 1, p. 763-782, 2013. Disponível em: http://numen.ufjf.emnuvens.com.br/numen/article/view/2126/1935. Acesso em: 25 set. 2017.

SARAMAGO, José. Um ateu preocupado com Deus. In: Saramago nas Suas Palavras. Edição e selecção de Fernando Gómez Aguilera, Lisboa: Editorial Caminho, 2010. 
RECEBIDO em 31/03/19

APROVADO em 18/07/19 